\title{
Estimating the number of children in households with substance use disorders in Germany
}

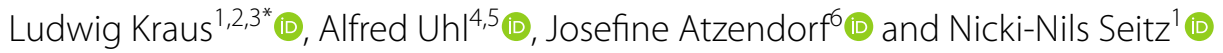

\begin{abstract}
Background: Parental substance misuse is reported to endanger the health and psychological development of children and adolescents. The aim of the present study was to address conceptual and methodological problems in estimating the number of children affected by parental substance misuse (CaPSM) and offer a novel approach based on survey data.

Methods: Data came from the 2018 German Epidemiological Survey of Substance Abuse (ESA) among 18- to 64-year-olds ( $n=9267)$ and from population statistics. DSM-IV diagnostic criteria were used to assess substance use disorder (SUD) related to tobacco, alcohol, cannabis, cocaine or amphetamine. Based on the number of household members, the number of children below age 18 years and the information on SUD status of the respondent living in this household, the number of children currently living in households with at least one member with SUD was estimated.
\end{abstract}

Results: In 2018, there were 13,597,428 children younger than 18 years living in Germany. Of these, $6.9-12.3 \%$ $(935,522-1,673,103)$ were estimated to currently live in households where at least one adult had a tobacco use disorder, $5.1-9.2 \%(688,111-1,257,345)$ in households where at least one adult had an alcohol use disorder and 0.6-1.2\% $(87,817-158,401)$ in households where at least one adult had a disorder related to the use of illicit drugs.

The total number of children currently living with SUD adults in their household was estimated at 11.2-20.2\% $(1,521,495-2,751,796)$.

Conclusions: Available estimates are difficult to interpret and to compare due to a lack of clear case definitions and methodological approaches with various biases and limitations. Future estimates need to provide precise case definitions and standard approaches.

Keywords: Children, Adolescents, Parental substance misuse, Estimation, Germany

\section{Background}

Parental substance misuse (PSM) is reported to endanger the healthy development of children and adolescents. These children and adolescents are at increased risk of negative outcomes such as emotional, social and

*Correspondence: kraus@ift.de

${ }^{1}$ IFT Institut für Therapieforschung, Leopoldstraße 175, 80804 München, Germany

Full list of author information is available at the end of the article behavioural adjustment problems as well as deficits in cognitive and academic functioning [1-3]. They also face a higher risk of early substance use involvement as well as mental health problems [4, 5]. For instance, anxiety disorder [6], depression [7, 8], attention-deficit/hyperactivity disorder $[9,10]$ and also disturbed social behaviour $[11,12]$ were more common in the children and adolescents of parents with substance use disorder (SUD) compared with the offspring of parents without SUD. 
PSM is often associated with problematic parenting, mood swings, disinhibited behaviour and unmet parental responsibilities [13, 14]. Older children of substancemisusing parents must sometimes step in to fulfill the role of their parents such as feeding a baby or taking care of younger siblings while parents experience withdrawal symptoms or recover from a hangover [15]. Parental and family problems often lead to an atmosphere in the home of fear, chaos, uncertainty, secrecy and stigma of living with these problems [16]. Furthermore, unstable parent-child relationships resulting from separation from or death of a parent, conflicts, aggression and violence in the family aggravate these adverse living conditions $[17$, 18].

\section{Theoretical considerations}

Estimating the number of children affected by parental substance misuse (CaPSM) constitutes a major challenge on account of the definition of exposure. A lifetime approach assesses how many children were exposed to substance-misusing (SM) parents or other carers during childhood and adolescence, resulting in a prevalence until maturity. This can be achieved using a retrospective approach by asking young adults older than, for instance, 18 years about their experience with PSM during childhood and adolescence. The number of people who were affected by PSM in the course of their childhood and adolescence as well as the number of people not affected can be directly assessed and the percentage of children affected by PSM can be calculated (see [19, 20]). However, such approaches need to account for the time-varying nature of exposure, e.g. parents' or carers' substance use may be episodic, or they may episodically be present and absent from their children's lives as a result of parental desertion, child removal or otherwise. Conversely, a current approach quantifies the number of CaPSM who are exposed to PSM by parents or other adults they are presently cohabiting with (see, [21, 22]).

Although the majority of children live with their biological parents, estimates including only biological parents neglect potentially adverse conditions of children living with social parents with substance use problems, or where significant others they are living with are misusing substances (see [23]). Social parents may be step, adoptive or foster parents, grandparents or other relatives. Other cohabiting adults who are not legal guardians may be new partners of a parent, grandparents, older siblings, other relatives or other people within a flat- or house-sharing community (see [22]). However, many biological parents, social parents or significant others with substance use problems never lived in the same household as their minor offspring or do not live with them anymore, but may nevertheless have affected the child's wellbeing.

Of similar importance are the pattern and severity of substance use problems considered. What is labelled 'excessive' or 'problematic' substance use is much more prevalent than 'pathological' substance use, in the sense of SUD (see [22]). Thus, the estimated number of children at risk of experiencing harm is highly dependent on the type of exposure considered as potentially causing harm. Yet another crucial aspect is the particular substance the parent or carer is misusing. The impact of parental dependent tobacco smoking on children is obviously very different from the impact of misusing alcohol or using strongly intoxicating and mind-altering substances $[13,14,24]$.

Thus, the existing estimates of the number of CaPSM broadly differ in terms of the chosen definitions of exposure and, consequently, estimates accounting for exposure during childhood and adolescence will be higher than measures of current exposure, and restricting exposure to biological parents will result in lower estimates than a definition including socially transmitted risks from close relatives or significant others living in the same household. Finally, defining exposure as excessive substance use or SUD of parents or cohabiting adults will clearly affect the estimate.

\section{Methodological considerations}

The majority of the rather few estimates of the number of CaPSM take the perspective of current rather than lifetime exposure and are based on household surveys. By selecting households and collecting all necessary information on adult household members and the number of children living with them, the number of children currently affected by SM adults as well as the number of children not affected can be estimated [22, 23, 25-27]. Of these surveys, the majority are based on an individual household member approach (IHMA) where only one adult in a selected household is interviewed [22, 23, 25, 27]. Based on a SM assessment of the selected respondent, the number of children living in the household and information on the respondent-child relationship, the number of CaPSM has been estimated. As the SM status of other adult members living in the same household as the respondent is usually not assessed in household surveys, the number of CaPSM using the IHMA approach assumes that there is no more than one adult with SM status living in the household.

Information on the number of children affected by SUD of adults is needed in order to address specific needs for health care initiatives and professional as well as non-professional support. A significant caveat of surveys based on the prevailing IHMA approach is the 
implicit assumption that only one adult per household may be affected with SUD, resulting in an overestimate due to multiple counting in cases where there is more than one adult affected by SUD. In the present paper, we offer a novel approach to overcome this limitation by assuming two extremes when identifying a SUD-positive adult in a household: only one adult is or all adults are affected by SUD. This results in a lower and upper threshold of the number of CaPSMs. As case definition of CaPSM, we focus on current SUD problems of cohabitating adults including biological and social parents as well as other adults living in the same household, such as older siblings. Parents not currently living in the household are not considered. Children or adolescents under age 18 years living in the same household are defined as the target population. Although any substance use may affect a person's control over emotions, judgements or behaviour negatively, we restrained our estimates to the more severe conditions of SUD as defined by the DSM- 5 criteria [28]. The psychoactive substances considered in relation to SUD were tobacco, alcohol and illicit substances such as cannabis, cocaine or amphetamine.

\section{Methods \\ Data}

Estimates were based on data from the German Epidemiological Survey of Substance Abuse (ESA) conducted in 2018 [29] and on data on population statistics [30]. The sample includes German-speaking individuals aged between 18 and 64 years living in private households. A multistage sample selection was performed: first, 254 municipalities (sample points) were randomly selected followed by a random selection of the target population from population registers. Data were collected by standardized self-administered questionnaires (paper-pencil), telephone interviews or online questionnaires. The adjusted sample included 9267 individuals (response rate: 41.6\%). Details on the methods and design of the ESA 2018 have been published elsewhere [27].

In the section on demographics in ESA 2018, participants were asked about both the number of children under the age of 18 years and the number of adults including the respondent who currently lived in their household. Moreover, information about the family status of the respondents (married/partnership, divorced, widowed), whether children were present and the relationship with each child (biological, step, adoptive or foster parent, brother or sister, nephew or niece, other) was collected. SUD related to tobacco, alcohol, cannabis, cocaine or amphetamine was assessed using the criteria of the DSM-5 at the respondent level, but no information about the SUD status of other adults in the household was collected (IHMA approach). Diagnoses were based on the Munich Composite International Diagnostic Interview (M-CIDI; 31, 32).

\section{Analysis}

The analysis was based on the study participants' information on the number of people living in their households, the number of children below age 18 years living in these households and information on the participants' SUD status. Owing to the low number of individuals fulfilling criteria for disorders related to cocaine $(n=16)$ or amphetamine $(n=28)$, these disorders were combined with cannabis-related disorder and labelled illicit substance use disorders'. As the sample represents individuals in the adult population, it is assumed that the results are proportional to a full census covering the target population. In a full census, every household with more than one adult would result in the same children being counted multiply as they are related to more than one adult. Children indicated by an SUD-affected adult would be considered to be CaPSMs and, if they are indicated by another adult from this household without a SUD problem, they would be counted erroneously as non-CaPSMs. For instance, considering six children in a household with three adults and adding up the number of all children would incorrectly result in 18 children, even though there are actually only six. To avoid multiple counting, the share of children per adult needs to be considered. By dividing the number of children related to each respondent by three (share of children per adult), the total sum over all adults represents the correct number of children in each household $6 / 3+6 / 3+6 / 3=6$.

When counting the number of SUD-affected children based on the number of children reported by the adults in each household, the fundamental problem arises that children living with a surveyed non-SUD-affected parent are counted as non-CaPSM even though they may be living in a household with another SUD-affected adult and therefore should be classified as CaPSM. As the SUD status of other adults per household was not assessed in the ESA, there is no precise way to compensate for this shortcoming. However, it is possible to calculate a lower and an upper point estimate for the number of children affected by SUD in households by applying the two most extreme diametrical assumptions:

Assumption 1: All surveyed respondents, regardless of being SUD-positive or SUD-negative, cohabit exclusively with adults with the same SUD status. If this is the case, all children in the population are correctly classified as SUD affected or not.

Assumption 2: No more than one adult in each household is affected by SUD. In this case, all children mentioned by SUD-negative adults in house- 
holds with SUD-positive adults are erroneously classified as 'non-SUD affected'.

For each individual in the sample, three variables were used: the number of children in the household $\left(n_{c}\right)$, the number of adults in the household $\left(n_{a}\right)$ and the SUD status $i$ of the surveyed adult $(i \in\{S U D, n o n S U D\})$. Based on Assumption 1 and adding the share of children per adult for all households, the number of SUD-affected children $\left(N_{S U D .1}\right)$ and the number of non-SUD-affected children $\left(N_{\text {nonSUD.1 }}\right)$ was calculated:

$$
\begin{aligned}
& N_{S U D .1}=\sum_{i=S U D} \bar{n}_{c} \cdot n_{a} \\
& N_{\text {nonSUD.1 }}=\sum_{i=\text { nonSUD }} \bar{n}_{c} \cdot n_{a}
\end{aligned}
$$

Under Assumption 1, adding the shares of children for all SUD adults represents the correct number of children affected by SUD in the households, as Assumption 1 rules out the possibility that SUD-negative adults live in the same households with SUD-positive adults. For example, if there are six children living in a household with three SUD-positive adults, the share of children for each adult is two and all children are CaPSMs. Summing the share of children for the three SUD-positive adults adds up correctly to six affected children $(3 * 2=6)$.

Under Assumption 2, we are confronted with the situation in which the shares of children linked to SUDnegative adults who are actually affected by other SUD-positive adults living in the same households are misclassified. Assuming that there is no more than one SUD-positive adult in every household, all other adult household members must be SUD negative. The total number of misclassified shares of children (adjustment term) needs to be subtracted from the number of initially (in line with Assumption 1) classified unaffected children $N_{\text {nonSUD.1 }}$ and added to the number of children initially classified as affected $N_{S U D .1}$. For example, if there are six children in a household with two non-SUD adults and one SUD adult, all six children are affected by SUD, but only the SUD adult's children share is initially considered as affected $(1 * 2=2)$, even though six children are actually affected. The difference of four children must be compensated for to arrive at correct estimates. Using the adjustment term

$$
N_{a d j}=\sum_{i=S U D} \bar{n}_{c} \cdot\left(n_{a}-1\right)
$$

the number of SUD-affected children $\left(N_{S U D .2}\right)$ and the number of non-SUD-affected children $\left(N_{\text {nonSUD.2 }}\right)$ in line with Assumption 2 were calculated as follows:

$$
N_{S U D .2}=N_{S U D .1}+N_{a d j}
$$

$$
N_{\text {nonSUD. } 2}=N_{\text {nonSUD. } 1}-N_{\text {adj }}
$$

The percentage of affected children $\frac{N_{\text {SUD }}}{N_{S U D}+N_{\text {nonSUD }}}$ reflecting the proportion of SUD-affected children among all children was calculated under both assumptions. Under Assumption 1, $\frac{N_{S U D .1}}{N_{S U D .1}+N_{\text {nonSUD. } 1}}$ yields the lower point estimate and, under Assumption 2, $\frac{N_{S U D .2}}{N_{S U D .2}+N_{\text {nonSUD. }}}$ yields the upper point estimate.

Lower and upper point estimates of $N_{S U D .1}$ and $N_{\text {nonSUD.1 }}$ as well as $N_{S U D .2}$ and $N_{\text {nonSUD.2 }}$ were calculated separately for the conditions of tobacco, alcohol and illicit substance use disorders. Multiplying the obtained point estimates by the number of children younger than 18 years in the population $(\mathrm{N}=13,597,428$ as of 31 December 2018; [30]), the range in the number of children living in households with at least one member having a positive SUD diagnosis was projected to the total population. All analyses based on survey data were performed using Stata 15.1 (Stata Corp LP; College Station, TX, USA).

\section{Results}

The 12-month prevalence of SUDs is shown in Table 1 . The prevalence of SUDs in adults ranged between 1.6\% for illicit drug use disorder, $8.5 \%$ for alcohol use disorder and $15.5 \%$ for tobacco use disorder.

The family status of SUD and non-SUD families differed statistically significantly. More than two thirds (72.5\%) of non-SUD respondents were married or had a partner, whereas the proportion was significantly lower in respondents with SUD status (49.4\%) and lowest among respondents with illicit substance use disorder (20.0\%; Table 2). On average, 1.7 children were living in non-SUD households and 1.6 in SUD households. In non-SUD households, $85.0 \%$ of children lived with biological parents, whereas in SUD households, $68.1 \%$ did; this difference was statistically significant $(p \leq 0.01)$. The proportion of single parent/carer families was lower in non-SUD households (6.1\%) than in SUD households

Table 1 12-month prevalence of substance use disorders according to DSM-5 among 18- to 64-year-olds

\begin{tabular}{llcl}
\hline Substance & $\mathbf{n}$ & $\%$ & {$[\mathbf{9 5 \% ~ C l}]^{\mathbf{a}}$} \\
\hline Tobacco & 1140 & 15.5 & {$[14.4 ; 16.7]$} \\
Alcohol & 973 & 8.5 & {$[7.8 ; 9.2]$} \\
Illicit drugs $^{\text {b }}$ & 176 & 1.6 & {$[1.3 ; 2.0]$} \\
\hline
\end{tabular}

a $95 \%$ confidence interval

${ }^{b}$ cannabis, cocaine or amphetamine 
Table 2 Sample characteristics in households with children by adult SUD status: number of adults in household, age of respondent, family status of respondent; number of children in household and relationship with adult

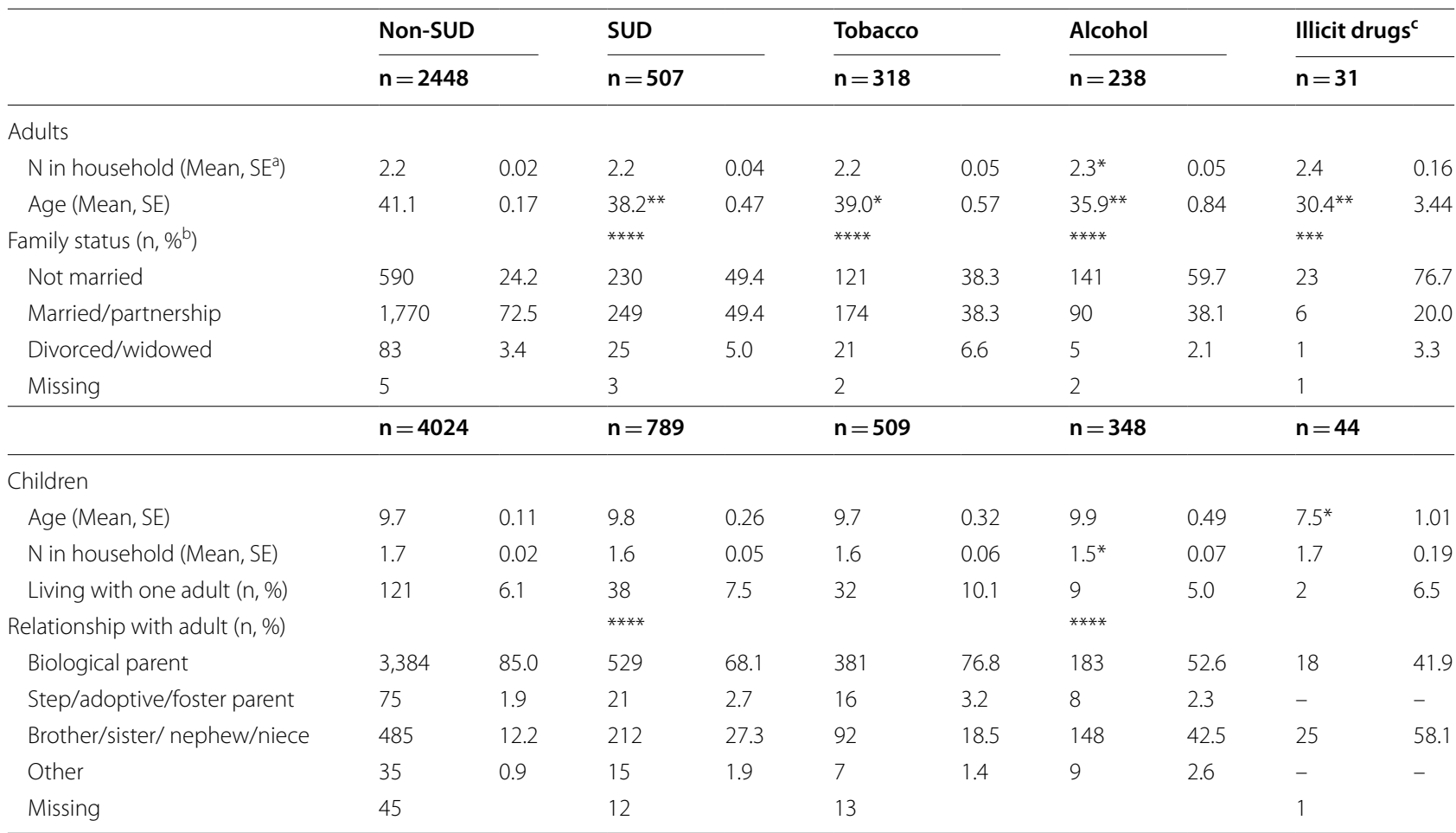

${ }^{a}$ Standard error

$\mathrm{b} \%$ of valid cases

${ }^{c}$ Cannabis, cocaine or amphetamine

${ }^{*}$ adjusted Wald test with non-SUD, $\mathrm{p} \leq 0.05$; ${ }^{* *}$ adjusted Wald test with non-SUD, $\mathrm{p} \leq 0.01 ;{ }^{* * *}$ Chi $^{2}$ test with non-SUD, $\mathrm{p} \leq 0.05 ;{ }^{* * * *}$ Chi ${ }^{2}$ test with non-SUD, $\mathrm{p} \leq 0.01$

Table 3 Estimated number of children in households with at least one adult affected by type of substance use disorder and prevalence among all children below age 18 years

\begin{tabular}{|c|c|c|c|c|}
\hline \multirow[t]{2}{*}{ Substance } & \multicolumn{2}{|c|}{$\begin{array}{l}\text { Estimated number of } \\
\text { affected children }(\mathrm{N})\end{array}$} & \multicolumn{2}{|c|}{$\begin{array}{l}\text { Prevalence among } \\
\text { all children (\%) }\end{array}$} \\
\hline & $\begin{array}{l}\text { Lower } \\
\text { limit }\end{array}$ & $\begin{array}{l}\text { Upper } \\
\text { limit }\end{array}$ & $\begin{array}{l}\text { Lower } \\
\text { limit }\end{array}$ & $\begin{array}{l}\text { Upper } \\
\text { limit }\end{array}$ \\
\hline Tobacco & 935,522 & $1,673,103$ & 6.9 & 12.3 \\
\hline Alcohol & 688,111 & $1,257,345$ & 5.1 & 9.2 \\
\hline Illicit drugs ${ }^{\mathrm{b}}$ & 87,817 & 158,401 & 0.6 & 1.2 \\
\hline \multicolumn{5}{|l|}{ Total } \\
\hline Excluding tobacco & 726,624 & $1,327,223$ & 5.3 & 9.8 \\
\hline Including tobacco & $1,521,495$ & $2,751,796$ & 11.2 & 20.2 \\
\hline
\end{tabular}

a 13,597,428 children aged < 1 to 17 years; Population Statistics 2018 (Statistisches Bundesamt (Destatis) 2019)

${ }^{b}$ Cannabis, cocaine or amphetamine

(7.5\%), but the difference did not reach statistical significance.

The estimates of the number of children in households with adults affected by SUD and the prevalence of affected children among all children are presented in
Table 3. The results based on single substance disorders of adults suggest that the highest proportion of affected children live in households with at least one adult with a tobacco use disorder (lower and upper estimate: 6.9$12.3 \%)$. The proportion of children living in households with at least one adult affected by alcohol use disorder range between 5.1 and 9.2\%, and between 0.6 and $1.2 \%$ of children live in households with at least one adult with illicit drug use disorders. Considering double and multiple SUDs but excluding tobacco use disorder, we estimated between 5.3 and $9.8 \%$ or 726,624 and $1,327,223$ affected children. Including tobacco use disorder, a total of $11.2-20.2 \%$ or $1,521,459-2,751,796$ children were estimated to live in households with at least one SUDaffected adult.

\section{Discussion}

Using a representative survey of adults and information on their SUD status as well as the number of adults and children currently living in the same household with the respondent, the number of SUD-affected children cannot be precisely estimated. Not knowing the SUD status of non-surveyed adults in the household, summing the 
number of children reported by each respondent would overestimate the total number of children as a result of multiple counting. This problem can be solved by calculating the share of children per adult and by assuming that, whenever a surveyed adult is SUD affected: (1) all other adults in the household are SUD positive as well or (2) all other adults are SUD negative. The first assumption results in a conservative lower point estimate of SUDaffected children, whereas the second assumption results in an upper point estimate by both aggregating the share of children per adult for every household (dividing the number of children by the number of adults) and adjusting for children misclassified as non-CaPSM because the person interviewed was SUD negative even though another adult in the household was SUD positive.

It is important to note that the cross-sectional perspective of childrens' current exposure to SUD taken in the present approach misses all occasions related to SUD cohabiting adults before the assessment and all occasions that will occur later until the children are of age. In comparison with this, if adult respondents were asked whether, during their childhood and adolescence, they were affected by the substance use of a parent or another adult they were closely related to, a retrospective approach including all past experiences would be taken resulting in a higher number of affected children.

\section{Comparisons with national and international estimates}

In 2018, the number of children below the age of 18 years in households with SUD in Germany was estimated at 112-202 per 1000 children. Excluding exposure to tobacco use disorder, the result was 53-98 per 1000 children. Compared with an earlier estimate of 2.65 million children who were ever living with parents with alcohol use disorder by Klein [33], our estimate $(688,111-$ $1,27,345)$ is considerably lower. Naturally, asking $14-$ to 24-year-olds from a community sample about lifelong exposure to parental alcohol use problems [25] will result in a higher estimate. The second German estimate of 6.6 million affected children is based on the approach described above but implicitly only on Assumption 1 [34]. Moreover, different from our definition, the authors of this study used the AUDIT-C, i.e. a score of five or more points for men and four or more points for women, to define alcohol use problems. Using less severe criteria of risky drinking in terms of frequency and quantity of drinking and frequency of heavy drinking occasions naturally increases the number of exposed children.

Comparisons with international estimates are similarly limited because of different definitions of exposure and substance use problems among parents, carers or adults living in the same household. The proportion of children under 20 years with one or both parents misusing alcohol was estimated at $10.7 \%$ in Denmark, $5.7 \%$ in Finland, $15.4 \%$ in Germany and between 17 and $23 \%$ in Poland [35]. Alcohol misuse by parents was labelled 'alcohol problems' in Denmark, 'excessive alcohol use' in Finland, 'alcoholism' in Germany and 'alcohol addiction' or 'alcohol abuse' in Poland. Similarly, estimates for the proportion of children under 20 years with one or both parents using drugs was $0.2 \%$ in both Denmark and Germany and $1.5-2.4 \%$ in the UK. The definition ranged from drug use in Denmark to drug dependency in Germany and serious drug problems in the UK. Using a similar definition to the one in our study and conducting secondary analyses of data from national household surveys, a study in the UK estimated the proportion of children below the age of 12 years currently living in a household with an alcohol-dependent adult at $5.9 \%$ and children currently living in a household with a drug-dependent adult at $2.8 \%$ [22]. Grant [26] used data from the 1992 National Longitudinal Alcohol Epidemiological Survey and calculated the rate of children aged 17 years or younger living in households with one or more adults who were abusing or dependent on alcohol (last 12 months) and who, at some time in their lives, had abused or were dependent on alcohol, resulting in a lower (15\%) and upper estimate (43\%). Excluding non-parental relationships with the child in the household, Bassani and colleagues [23] estimated that $11.4 \%$ and $8.3 \%$ of children aged under 12 years in Canada were exposed to SUDs and alcohol use disorders (i.e. excluding illicit substances) of their biological parents respectively.

\section{Potential risks of harm}

Although our findings suggest that between 11.2 and $20.2 \%$ of all children in Germany are living in households with at least one adult with any SUD, these children may be subject to different risks depending on the type and severity of the disorder. For instance, children living in households where adults smoke have a higher risk of somatic diseases such as asthma and other respiratory conditions [36, 37], whereas children exposed to intoxicated cohabitants are more likely to face psychologically stressful situations leading to lower school performance or behavioural problems [38-40]. This can be neglect, aggression or having to take over parental roles. Children of parents with SUD generally have a higher risk of drug involvement as well as mental health problems or disturbed social behaviour compared with the offspring of parents without SUD [4, 41]. Research also indicates that these children are at higher risk of developing SUDs themselves, as well as non-substance-related psychopathologies [42].

Respondents with SUD in our study were more often living in single parent/carer households compared with 
non-SUD respondents, indicating the need for supportive strategies for these parents and children. There is evidence that young people raised by single parents are more likely to perform poorly in school and partake in deviant behaviours such as smoking, substance use and crime [43].

It is also important to point out that estimates of the number of children affected by parental SUD indicate a potential risk of adversity. Quantitative and qualitative aspects, such as the frequency and intensity of the adults' problematic SUD-related behaviours, are not considered in any study. For instance, some children may be exposed to SUD adults in their household who often behave violently when intoxicated, or who are depressed and stress their children with suicidal ideas. Others may live with adults who primarily damage their own physical health through excessive alcohol or drug consumption and only slightly affect the children in their environment. Despite experiencing negative somatic, psychological or social consequences, some children do not show signs of negative psychological developments on account of factors of resilience supporting these children in developing stable and assertive personalities [44-47].

\section{Notes on prevention}

There is ample evidence that parents and carers of children with SUD have strong and often irreversible negative somatic and psychological effects on the wellbeing of their children. To target these children, prevention programmes and policies have been developed [15, 48, 49]. For instance, secondary prevention targeting individual, familial and environmental influences by offering specific help to affected children and parents has been proven effective in reducing future problems in these children [50]. In addition to providing preventive support for parents with SUD and affected children, the harmful effects of SUD on others and particularly on children need to be recognized as a public health concern in the same way as are the harmful effects on the users or the costs to society [51].

\section{Strengths and limitations}

To account for multiple counting of children in households where more than one adult lives, we based our calculations on the share of minors per adult in every household. Under Assumption 1, aggregating these shares per SUD adult and non-SUD adult provides an estimate of the number of SUD-affected and non-SUDaffected children in the sample. Under Assumption 2, we compensated for the percentage of shares of children associated with non-SUD adults in households where children are affected by another SUD adult. Finally, the percentage of SUD-affected children could be calculated without having to resort to total population figures under both assumptions.

However, the availability of data on SUDs in our study was limited to disorders related to the use of tobacco, alcohol, cannabis, cocaine or amphetamine. These data may account for the majority of substance-related disorders in the population, but SUD coverage is not comprehensive. Estimates of SUDs from survey data are usually subject to underreporting because of higher non-response in particular subgroups or socially desirable response behaviour. For instance, surveys usually miss subgroups with higher risks of SUDs such as people who are homeless, in prison, hospitalized or living in institutions at the time of the survey. Moreover, biases may be caused by systematic non-participation. The ESA is subject to a 'middle-class bias', i.e. individuals with low socioeconomic status are under-represented, challenging the representativeness of the data [52]. Finally, household surveys are cross-sectional in nature with respondent substance use and parental status measured at a single point in time; yet these are not stable factors but fluctuate over time.

\section{Conclusions}

To conclude, estimates of the number of CaPSM can vary substantially due to several aspects. The observation may refer to the total lifetime of children and youths until reaching adulthood, the period until the assessment or the current situation. The methodological approaches may assess alcohol use patterns of adults cohabiting with minors or ask adult CaPSMs about their experiences with SUD-positive parents or other adults cohabiting with them during childhood and adolescence. Assessments may consider the SUD status of the interviewed adult or the SUD status of other household members as well. Exposure may be defined as excessive use, problematic use or substance use disorder. Finally, respective SUD adults may be biological or social parents, and/or significant others, who are living in the same household, and/or biological parents living elsewhere. In order to identify changes in exposure to risk in relation to the child's age, future approaches would benefit from longitudinal or cohort study designs with multiple and regular assessment intervals. Most importantly, future estimates need to provide precise case definitions, and standard approaches need to be developed that include unequivocal definitions and descriptions of methodological approaches to avoid or compensate for biases. Only if this has been realized can CaPSM estimates be sensibly interpreted and compared with estimates stemming from other studies. 


\section{Abbreviations}

CaPSM: Children affected by parental substance misuse; ESA: Epidemiological Survey of Substance Abuse; IHMA: Individual household member approach; PSM: Parental substance misuse; SM: Substance misuse; SUD: Substance use disorder.

\section{Acknowledgements}

Not applicable.

\section{Authors' contributions}

LK, NNS and AU designed the study. NNS and AU conducted the statistical analysis. LK wrote the manuscript. All authors critically contributed to earlier drafts of the manuscript and approved the final version of the paper.

\section{Funding}

Open access funding provided by Stockholm University. Funding for the 2018 Epidemiological Survey of Substance Abuse (ESA) was provided by the German Federal Ministry of Health (Bundesministerium für Gesundheit, BMG) (ref: ZMVI1-2517DSM200). The funder had no role in the study design, data collection and analysis, decision to publish or preparation of the manuscript.

\section{Availability of data and materials}

All datasets from the Epidemiological Survey of Substance Abuse (since 1980) are available for scientific purposes at GESIS Leibniz Institute for Social Research and can be requested there. Permission to access the data must be obtained from the IFT Institut für Therapieforschung in Munich, Germany.

\section{Declarations}

\section{Ethics approval and consent to participate}

All participants received written correspondence comprising study information, a data privacy statement, an online access code and an accompanying letter from the German Federal Ministry of Health. Informed consent was given either verbally (telephone arm), by ticking the informed consent box (online questionnaire) or by accepting the conditions (study content, data protection, data processing and storage) in sending back the filled-in questionnaire. Participants were informed about the voluntary nature of their participation and confidentiality of their data. The questionnaire and methodology of the Epidemiological Survey of Substance Abuse (EAS) received ethical approval from the ethics committee of the German Psychological Society (DGPs; Reg. No: GBLK06102008DGPS)

\section{Consent for publication}

Not applicable.

\section{Competing interests}

All authors state that they do not have any competing or conflicting interests related to the work presented in the paper.

\section{Author details}

'IFT Institut für Therapieforschung, Leopoldstraße 175, 80804 München, Germany. ${ }^{2}$ Department of Public Health Sciences, Centre for Social Research On Alcohol and Drugs, Stockholm University, Stockholm, Sweden. ${ }^{3}$ Institute of Psychology, ELTE Eötvös-Loránd-University, Budapest, Hungary. ${ }^{4}$ Austrian Public Health Institute, Vienna, Austria. ${ }^{5}$ Sigmund Freud Private University, Vienna, Austria. ${ }^{6}$ Munich Center for the Economics of Aging (MEA), MaxPlanck-Institute for Social Law and Social Policy, Munich, Germany.

Received: 20 July 2020 Accepted: 26 October 2021

Published online: 06 November 2021

\section{References}

1. Chassin L, Pitts SC, DeLucia C. The relation of adolescent substance use to young adult autonomy, positive activity involvement, and perceived competence. Dev Psychopathol. 1999;11(4):915-32.

2. Hussong AM, Flora DB, Curran PJ, Chassin LA, Zucker RA. Defining risk heterogeneity for internalizing symptoms among children of alcoholic parents. Dev Psychopathol. 2008;20(1):165-93.
3. Hussong AM, Wirth RJ, Edwards MC, Curran PJ, Chassin LA, Zucker RA. Externalizing symptoms among children of alcoholic parents: entry points for an antisocial pathway to alcoholism. J Abnorm Psychol. 2007;116(3):529-42.

4. Solis JM, Shadur JM, Burns AR, Hussong AM. Understanding the diverse needs of children whose parents abuse substances. Curr Drug Abuse Rev. 2012;5(2):135-47.

5. Waldron M, Vaughan EL, Bucholz KK, Lynskey MT, Sartor CE, Duncan AE, et al. Risks for early substance involvement associated with parental alcoholism and parental separation in an adolescent female cohort. Drug Alcohol Depend. 2014;138:130-6.

6. MacPherson PS, Stewart SH, McWilliams LA. Parental problem drinking and anxiety disorder symptoms in adult offspring: examining the mediating role of anxiety sensitivity components. Addict Behav. 2001;26(6):917-34.

7. Hill SY, Tessner KD, McDermott MD. Psychopathology in offspring from families of alcohol dependent female probands: a prospective study. J Psychiatr Res. 2011:45(3):285-94.

8. Fuller-Thomson E, Katz BR, Phan TV, Liddycoat PMJ, BrennenstuhI S. The long arm of parental addictions: the association with adult children's depression in a population-based study. Psychiatry Res. 2013;210:95-101.

9. Parvaresh N, Mazhari S, Nazari-Noghabi M. Frequency of psychiatric disorders in children of opioid- or methamphetamine-dependent parents. Addict Health. 2015;7:140-8.

10. Kendler KS, Ohlsson H, Sundquist K, Sundquist J. Cross-generational transmission from drug abuse in parents to attention-deficit/hyperactivity disorder in children. Psychol Med. 2016:46:1301.

11. Waldron M, Martin NG, Heath AC. Parental alcoholism and offspring behavior problems: findings in Australian children of twins. Twin Res Hum Genet. 2009;12(5):433-40

12. Molina BS, Donovan JE, Belendiuk KA. Familial loading for alcoholism and offspring behavior: mediating and moderating influences. Alcohol Clin Exp Res. 2010;34(11):1972-84.

13. McKeganey N, Barnard M, McIntosh J. Paying the price for their parents' addiction: meeting the needs of the children of drug-using parents. Drug-Educ Prev Polic. 2002;9(3):233-46.

14. Dyba J, Moesgen D, Klein M, Leyendecker B. Mothers and fathers in treatment for methamphetamine addiction-parenting, parental stress, and children at risk. Child Fam Soc Work. 2019;24:106-14.

15. Barnard M, McKeganey N. The impact of parental problem drug use on children: what is the problem and what can be done to help? Addiction. 2004:99(5):552-9.

16. Velleman R, Templeton LJ. Impact of parents'substance misuse on children: an update. B J Psych Advances. 2016;22:108-17.

17. Waldron M, Bucholz KK, Lynskey MT, Madden PA, Heath AC. Alcoholism and timing of separation in parents: findings in a midwestern birth cohort. J Stud Alcohol Drugs. 2013;74(2):337-48.

18. Velleman $R$, Templeton $L$, Reuber D, Klein M, Moesgen D. Domestic abuse experienced by young people living in families with alcohol problems: results from a cross-European study. Child Abuse Rev. 2008;17:387-409.

19. Zlotnick C, Tam T, Robertson MJ. Adverse childhood events, substance abuse, and measures of affiliation. Addict Behav. 2004;29:1177-81.

20. Dube SR, Anda RF, Felitti VJ, Croft JB, Edwards VJ, Giles WH. Growing up with parental alcohol abuse: exposure to childhood abuse, neglect, and household dysfunction. Child Abuse Negl. 2001;25(12):1627-40.

21. Duffy P, Shaw C, Woolfall K, Beynon CM. Estimating the numbers of children of problematic drug users and their residential circumstances to inform United Kingdom research, policy and practice. Drug-Educ Prev Polic. 2010;17:470-84.

22. Manning V, Best DW, Faulkner N, Titherington E. New estimates of the number of children living with substance misusing parents: results from UK national household surveys. BMC Public Health. 2009;9:377.

23. Bassani DG, Padoin CV, Philipp D, Veldhuizen S. Estimating the number of children exposed to parental psychiatric disorders through a national health survey. Child Adolesc Psychiatry Ment Health. 2009;3(1):6.

24. Boldo E, Medina S, Oberg M, Puklova V, Mekel O, Patja K, et al. Health impact assessment of environmental tobacco smoke in European children: sudden infant death syndrome and asthma episodes. Public Health Rep. 2010;125(3):478-87.

25. Lachner G, Wittchen H-U. Familiär übertragene Vulnerabilitätsmerkmale für Alkoholmissbrauch und -abhängigkeit. In: Watzl H, Rockstroh B, 
editors. Abhängigkeit und Missbrauch von Alkohol und Drogen. Göttingen: Hogrefe Verlag; 1997. p. 43-90.

26. Grant BF. Estimates of US children exposed to alcohol abuse and dependence in the family. Am J Public Health. 2000;90(1):112-5.

27. Dawe S, Frye S, Best D, Lynch M, Atkinson J. Evans C, Harnett PH. Drug use in the family: Impacts and implications for children. Canberra: Australian National Council on Drugs; 2007. https://www.academia.edu/28301909/ Drug_Use_In_the_Family_Impacts_and_Implications_for_Children

28. American Psychiatric Association. Diagnostic and statistical manual of mental disorders $\left(\mathrm{DSM}-5^{\circledR}\right)$. Washington, DC: American Psychiatric Association; 2013.

29. Atzendorf J, Rauschert C, Seitz N-N, Lochbühler K, Kraus L. The use of alcohol, tobacco, illegal drugs and medicines-an estimate of consumption and substance-related disorders in Germany. Dtsch Arztebl Int. 2019;116(35-36):577-84.

30. Statistisches Bundesamt (Destatis). Fortschreibung des Bevölkerungsstandes 2018. Ergebnisse auf Grundlage des Zensus 2011, Stichtag: 31.12.2018. 2019. https://www.destatis.de/DE/ZahlenFakten/Gesellscha $\mathrm{ftStaat/Bevoelkerung/Bevoelkerungsstand/Bevoelkerungsstand.html.}$ Accessed 4 Sep 2019

31. Wittchen H-U, Beloch E, Garczynski E, Holly A, Lachner G, Perkonigg A, et al. Münchener Composite International Diagnostic Interview (M-CIDI), Paper-pencil 2.2, 2/95. München: Max-Planck-Institut für Psychiatrie, Klinisches Institut: 1995.

32. Lachner G, Wittchen H-U, Perkonigg A, Holly A, Schuster P, Wunderlich U, et al. Structure, content and reliability of the Munich-Composite International Diagnostic Interview (M-CIDI) substance use sections. Eur Addict Res. 1998;4:28-41.

33. Klein M. Kinder und Jugendliche aus alkoholbelasteten Familien: Stand der Forschung, Situations- und Merkmalsanalyse, Konsequenzen. Regensburg: Roderer; 2005

34. Robert Koch Institut (RKI). Entwicklung von bundesweit aussagekräftigen Kennziffern zu alkoholbelasteten Familien (Abschlussbericht). Berlin: Robert Koch Institut; 2016.

35. European Monitoring Centre for Drugs and Drug Addiction (EMCDDA). Drugs and vulnerable groups of young people. Luxembourg; 2008.

36. DiFranza JR, Aligne CA, Weitzman M. Prenatal and postnatal environmental tobacco smoke exposure and children's health. Pediatrics. 2004;113(4 Suppl):1007-15.

37. Kwok MK, Schooling CM, Ho LM, Leung SS, Mak KH, McGhee SM, et al. Early life second-hand smoke exposure and serious infectious morbidity during the first 8 years: evidence from Hong Kong's "Children of 1997" birth cohort. Tob Control. 2008;17(4):263-70.

38. Berg L, Back K, Vinnerljung B, Hjern A. Parental alcohol-related disorders and school performance in 16-year-olds-a Swedish national cohort study. Addiction. 2016;111(10):1795-803.

39. Mensah FK, Kiernan KE. Parents' mental health and children's cognitive and social development: families in England in the Millennium Cohort Study. Soc Psychiatry Psychiatr Epidemiol. 2010;45(11):1023-35.
40. Olson JS, Crosnoe R. The interplay of peer, parent, and adolescent drinking. Soc Sci Q. 2018;99(4):1349-62.

41. Chassin L, Pitts SC, DeLucia C, Todd M. A longitudinal study of children of alcoholics: predicting young adult substance use disorders, anxiety, and depression. J Abnorm Psychol. 1999;108(1):106-19.

42. Clark DB, Cornelius J, Wood DS, Vanyukov M. Psychopathology risk transmission in children of parents with substance use disorders. Am J Psychiatry. 2004;161(4):685-91.

43. Antecol H, Bedard K. Does single parenthood increase the probability of teenage promiscuity, substance use, and crime? J Popul Econ. 2007;29:55-71.

44. Backett-Milburn K, Wilson S, Bancroft A, Cunningham-Burley S. Challenging childhoods: young people's accounts of getting by in families with substance use problems. Childhood. 2008;15:461-79.

45. Moe J, Johnson JL, Wade W. Resilience in children of substance users: in their own words. Subst Use Misuse. 2007:42:381-98.

46. Wlodarczyk O, Schwarze M, Rumpf HJ, Metzner F, Pawils S. Protective mental health factors in children of parents with alcohol and drug use disorders: A systematic review. PLoS ONE. 2017;12(6):e0179140.

47. Puhm A, Gruber C, Uhl A, Grimm G, Springer N, Springer A. Kinder aus suchtbelasteten Familien-Theorie und Praxis der Prävention (Monographie). Wien: LBI Sucht, Ludwig-Boltzmann-Institut für Suchtforschung am Anton-Proksch-Institut; 2008.

48. Botvin GJ, Griffin KW, DiazT, Scheier LM, Williams C, Epstein JA. Preventing illicit drug use in adolescents: long-term follow-up data from a randomised control trial of a school population. Addict Behav. 2000;25(5):769-74.

49. Olds DL, Sadler L, Kitzman H. Programs for parents of infants and toddlers: recent evidence from randomized trials. J Child Psychol Psychiatry. 2007:48(3-4):355-91.

50. Calhoun S, Conner E, Miller M, Messina N. Improving the outcomes of children affected by parental substance abuse: a review of randomized controlled trials. Subst Abuse Rehabil. 2015;6:15-24.

51. Room R, Laslett AM, Jiang H. Conceptual and methodological issues in studying alcohol's harm to others. Nordisk Alkohol Nark. 2016;33(5-6):455-78.

52. Piontek D, Kraus L, Gomes de Matos E, Atzendorf J. Der Epidemiologische Suchtsurvey 2015: Studiendesign und Methodik [The 2015 epidemiological survey of substance abuse: study design and methodology]. Sucht. 2015;2016(62):259-69.

\section{Publisher's Note}

Springer Nature remains neutral with regard to jurisdictional claims in published maps and institutional affiliations.

Ready to submit your research? Choose BMC and benefit from

- fast, convenient online submission

- thorough peer review by experienced researchers in your field

- rapid publication on acceptance

- support for research data, including large and complex data types

- gold Open Access which fosters wider collaboration and increased citations

- maximum visibility for your research: over 100M website views per year

At $\mathrm{BMC}$, research is always in progress.

Learn more biomedcentral.com/submissions 